\title{
Functionalized Calcium Carbonate as a Novel Pharmaceutical Excipient for the Preparation of Orally Dispersible Tablets
}

\author{
Tanja Stirnimann • Nicola Di Maiuta • Daniel E. Gerard • Rainer Alles • Jörg Huwyler • Maxim Puchkov
}

Received: 6 November 2012 / Accepted: 25 March 2013 / Published online: 19 April 2013

(C) Springer Science+Business Media New York 2013

\begin{abstract}
Purpose To overcome the limitation of insufficient hardness during the production of rapidly disintegrating orally dispersible tablets (ODTs). Furthermore, we investigated the properties and usefulness of functionalized calcium carbonate (FCC) as a new pharmaceutical excipient for the production of ODTs.

Methods A highly sensitive tensiometer-based method was developed to measure kinetics of weight loss during tablet disintegration. With this method we were able to determine the residence time of tablets placed on a basket immersed into a test medium. The shapes of tensiometer plots allowed us to categorize substances into four different types of disintegration. Results At the same volume and hardness, the tablet formulations with FCC showed a significantly higher porosity (over 60\%) than all other formulations. Residence time depended mainly on the tablet composition rather than on porosity. When combined with disintegrants, FCC formulations exhibited favorable disintegration properties, comparable to those of the marketed drug risperidone oro (disintegration time ca. $10 \mathrm{~s}$ ).

Conclusions Oral dosage forms - based on the new pharmaceutical excipient FCC - can be designed to have a short disintegration time combined with good mechanical strength. Due to these properties, FCC can be used for the preparation of ODTs.
\end{abstract}

KEY WORDS disintegration - ODT · porosity · residence time · tensiometer

T. Stirnimann $\cdot$ R. Alles $\cdot$ J. Huwyler $\cdot$ M. Puchkov $(\triangle)$

Department of Pharmaceutical Science

Division of Pharmaceutical Technology

University Basel, Klingelbergstrasse 50

4056 Basel, Switzerland

e-mail: maxim.puchkov@unibas.ch

N. Di Maiuta $\cdot$ D. E. Gerard

Omya Development AG, R\&D Microbiology, Baslerstrasse 42

$\mathrm{CH} 4665$ Oftringen, Switzerland

\section{INTRODUCTION}

Orally dispersible/disintegrating tablets (ODTs) constitute a solid, single-unit dosage form which instantaneously disperses/dissolves in the saliva (1). ODTs can be prepared by different techniques, such as freeze drying $(2,3)$, moulding (4), spray drying (5), and mass extrusion (6). Depending on the technique, the final form dissolves very rapidly (5$15 \mathrm{~s})$, but may be associated with low mechanical strength, high production costs, low drug content, or limited stability (7). The easiest technique to prepare ODTs is by direct compression. With conventional equipment, a limited number of process steps, and commonly available excipients, ODTs containing large amount of active ingredients can be produced at low costs. However, disintegration capacity of ODTs produced by this technique is limited by the size and hardness of the tablets $(8,9)$. Increased compression force applied during tableting leads to harder tablets thus increasing disintegration time (10). Consequently, ODTs with optimal disintegration properties are often small and/or have a low hardness and higher friability (8).

In accordance with the European Pharmacopeia, ODTs should disintegrate within $3 \mathrm{~min}$ when tested with the conventional disintegration apparatus (11). The American Food and Drug Administration (FDA) requires an in-vitro disintegration time of approximately $30 \mathrm{~s}$ or less $(12,13)$. The disadvantage of the conventional disintegration apparatus is poor discrimination among rapidly disintegrating tablets (14). Furthermore, the volume of the test medium $(900 \mathrm{ml})$ is relatively large, compared with the volume of saliva in the mouth cavity (less than $6 \mathrm{ml}$ ) (15). Several techniques have been proposed to measure the disintegration time of ODTs (14,16-23). For example, one research group used the force measurement detection to analyze the forces developed during the disintegration process due to water absorption (24). In our current work, we adapted the standard liquid 
absorption measurement by means of a tensiometer (25) to accurately determine tablet disintegration time and mimic disintegration in the patient's mouth cavity. This method employs the microbalance of the tensiometer to detect kinetics of weight loss during tablet disintegration. In addition, the proposed method provides quantitative information on dispersion kinetics, i.e., speed; ability to readily disperse in small volumes of liquid (e.g., teaspoon); and to detect formation of big swollen lumps.

Disintegration time of an ODT depends on the porosity of the tablet. The rate of water uptake increases with higher porosity of the ODT. Thus, disintegration rate increases because of faster wetting of the tablet (26). On the other hand, higher porosity of the ODT affects the hardness of the resulting tablets hence compromising further processing of formulations. Consequently, an ideal ODT combines two controversial properties, i.e., higher porosity and higher hardness. An excipient with combined functionality (highly porous and providing strong grip between particles) has been identified in paper industry.

Ridgway et al. modified a natural ground calcium carbonate to enhance porosity up to $60 \%(v / v)$ and enlarge the surface area. This functionalized calcium carbonate (FGG) absorbs water at a faster rate and is able to absorb 10 times more fluid than conventional calcium carbonate (27).

The manufacturing process of FCG shows some similarities to the production of precipitated calcium carbonate, an established pharmaceutical excipient. Both substances are produced by decomposition, once in aqueous solution (precipitated calcium carbonate) and once under acidic conditions (FGC). The different conditions and different concentrations lead to different shapes and different particle size distributions of the particles $(28,29)$.

The aim of the current work was to investigate the properties and usefulness of FCG as a new pharmaceutical excipient in the production of ODTs. Performance of FCC was compared to that of other commonly used excipients such as microcrystalline cellulose (MCG 102 and MCG burst), and FlowLac (fillers) and AcDiSol, VivaStar, and Kollidon CL as disintegrants.

\section{MATERIALS AND METHODS}

\section{Materials}

FCG (VP-220976 S02, Omya, Switzerland), directly compressible calcium carbonate (Barcroft ${ }^{\text {TM }}$ CS90, SPI Pharma, Germany), calcium carbonate (PharMagnesia CG Type Natur 120, Lehmann \& Voss \& Co., Germany), microcrystalline cellulose (MCG SANAQ ${ }^{\circledR}$ 102, Pharmatrans Sanaq AG, Switzerland), and lactose monohydrate (FlowLac ${ }^{\circledR} 100$, Meggle, Germany) were used as fillers. As disintegrating agents, modified cellulose gum (Ac-Di-Sol®, FMC, USA), insoluble, cross-linked polyvinylpyrrolidone (Kollidon ${ }^{\circledR} \mathrm{CL}$, BASF, Germany) and sodium starch glycolate (Vivastar ${ }$, JRS, Germany) were selected. A special kind of microcrystalline cellulose (MCG SANAQ ${ }^{\circledR}$ burst, Pharmatrans Sanaq AG, Switzerland) was used both as filler and disintegrant. The market ODT formulation, Risperidone-Mepha ${ }^{\circledR} 0.5$ oro tablets, was used as a reference of a market.

Isopropyl myristate (Hänseler AG, Switzerland) was chosen as a dispersant for particle size distribution measurements.

\section{Methods}

\section{Characterization of FCC}

The true density of FCG was determined by helium pycnometry (Micromeritics AccuPyc 1,330, USA).

Scanning electron microscopy (SEM) images were obtained using the FEI/Philips XL30 FEG apparatus (Philips, Netherlands). Before measurements, the samples were sputtered with a $40 \mathrm{~nm}$ gold layer by a sputter coating machine (MED 020, BalTec, Liechtenstein).

Pore size distribution of FCG was determined with a mercury porosimeter (AutoPore IV 9,500, Micromeritics Instrument, USA). Low-pressure mercury intrusion ranged from $3.59 \mathrm{kPa}$ to $206.64 \mathrm{kPa}$. During high-pressure mercury intrusion, the pressure ranged from $206.64 \mathrm{kPa}$ to 206.78 MPa. For both high- and low-pressure intrusion, equilibration time was $10 \mathrm{~s}$.

To measure the specific surface area, Nova 2000e (Quantachrome Instruments, USA) was used with the fivepoint BET (Brunauer, Emmett, Teller) method. After degassing the samples for $12 \mathrm{~h}$ at room temperature, the samples were measured with nitrogen at constant temperature (77.4 K). The measurement was performed in duplicate.

Particle size distribution was determined with the Mastersizer X long bed (Malvern Instruments, UK). For MCG 102, MCG burst, FlowLac, Barcroft, AcDiSol and VivaStar, the dry powder feeder (Malvern) was used. These measurements were performed in triplicate. Kollidon and FCG were dispersed in isopropyl myristate and then analyzed (in duplicate) by using the small volume sample presentation unit (Malvern). The medians of the particle diameter and their standard deviations are shown.

\section{Tablet Preparation}

All powders and formulations were mixed by using a tumbling mixer (Turbula T2C, Switzerland) for $10 \mathrm{~min}$ at $32 \mathrm{rpm}$. The tablets were compressed by a single punch press (Korsch EK0, Berlin) with $11 \mathrm{~mm}$ round flat tooling. The punch gap was adjusted to compact $500 \mathrm{mg}$ of FCC powder into a tablet with a hardness of $100 \mathrm{~N}$. The resulting tablet had a height of 
$5.30 \mathrm{~mm}$. This setting for the punch gap was kept constant for all other mixtures. The target hardness of $100 \mathrm{~N}$ was obtained by changing the mass of the compacts. The powder was introduced manually into the die. After compacting, the tablets were stored in closed glass bottles in the room at $24 \pm 2{ }^{\circ} \mathrm{C}$ and at $40 \pm 5 \%$ relative humidity (measured values) for 30 days to allow enough time for expansion.

We did not use any lubricant in order to avoid potential influence of the lubricant distribution on the properties of FGC in combination with a disintegrant. Due to manual tableting, the speed of compaction was slower than with an automated process, i.e. using hopper. The lower compression speed caused less friction; hence the tablets were not damaged during ejection.

We could obtain the same tablet hardness with $0.5 \%$ magnesium stearate. In order to exclude potential influence of lubricants, we compressed $300 \mathrm{mg} \mathrm{S02}$ powder at $4 \mathrm{kN}$. For the tablets without magnesium stearate, we obtained a hardness of $124 \pm 8 \mathrm{~N}$, whereas the tablets with magnesium stearate showed a hardness of $126 \pm 5 \mathrm{~N}$.

The concentration of the disintegrant was kept constant and comprises of $3 \% \mathrm{w} / \mathrm{w}$ in accordance to general recommendations (30). Our focus was set on the comparison of different filler excipients (e.g. FCG) on the disintegration behavior in presence of different disintegrants. In addition, our earlier experience in application of the percolation theory to the tablet disintegration and water uptake has revealed that the percolation threshold is located at $3 \% \mathrm{v} / \mathrm{v}$ for AcDiSol (31). This value could be corroborated by computer-based simulations of the percolation thresholds carried out by Garboczi et al. (32). In accordance with these results the optimal theoretical value lays in the area of $3 \%$ $v / v$ for elongated particles with aspect ratio approx. 20.

\section{Tablet Characterization}

To determine the mean tablet weight, tablets $(n=13)$ were weighted on an electronic balance (Mettler Toledo, type XS204 DeltaRange, Switzerland). Tablet diameter $(n=13)$ was measured with a micrometer screw (Mitutoyo Model CD-15CPX, Japan), and tablet thickness ( $n=13$ ) was determined with a dial indicator (Compac type $532 \mathrm{G}$, Switzerland). Friability was measured by an ERWEKA (type TA200, Germany). The hardness of the tablets $(n=3)$ was checked with a hardness tester (Tablet tester $8 \mathrm{M}$, Switzerland). To determine the true densities, a helium pycnometer was used (Micromeritics AccuPyc 1,330, USA). Porosity $\varepsilon(\%)$ of the tablets was calculated with the Eq. 1, as follows:

$\varepsilon=\left(1-\frac{\frac{\mathrm{m}}{\rho}}{\pi \cdot \mathrm{r}^{2} \cdot \mathrm{h}}\right) \cdot 100$ where $m$ is the tablet weight $(\mathrm{g}), \rho$ the true density of the powder mixture $\left(\mathrm{g} / \mathrm{cm}^{3}\right), \mathrm{r}$ the radius of the tablet $(\mathrm{cm})$, and $\mathrm{h}$ the height of the tablet $(\mathrm{cm})$.

\section{Method for Characterization of Disintegration and Dispersion Kinetics}

To characterize disintegration and dispersion kinetics of the tablets ( $n=3$, for FCC without disintegrants $n=2)$ a tensiometer (Krüss Processor Tensiometer K100MK2, Germany) was used. The experimental setup was composed of a special metal-wire basket (Fig. 1a) which was attached to the microbalance of the tensiometer with four nickel wires. For the measurement of small tablets (such as risperidone oro tablets), the mesh size was reduced by a nickel wire to a size of $4 \mathrm{~mm} \times$ $4.5 \mathrm{~mm}$. As shown in Fig. 1b, the basket was immersed to a defined depth (12 mm) into a beaker. The beaker was filled up to the edge with distilled water. The beaker was heated $\left(37^{\circ} \mathrm{C}\right.$ $\pm 1^{\circ} \mathrm{C}$ ) by the surrounding thermostatic water bath.

Weight loss versus time was recorded by the tensiometer software. Figure 1c shows a schematic representation of this plot. The tablet was placed manually on the basket immersed in the water. With the aid of the tensiometer software, the mass was plotted against the time. The time point at which the tablet reached the basket and disintegration induced by water absorption started was indicated as $t_{0}$. At this stage, the weight was increased due to water uptake. This was reflected as weight increase on the profiles. The weight decrease was explained as tablet disintegration upon water uptake. The end of tablet disintegration was indicated by the leveling off of the profile. This event was referenced as $t_{1}$. The difference between $t_{1}$ and $t_{0}\left(t_{1}-t_{0}\right)$ was the tablet residence time on the basket. Residence time is a measure of disintegration time and is a good indicator of the time needed to disperse the tablet in the mouth cavity or on a spoon. To determine $t_{0}$ and $t_{1}$, the two linear equations were fitted with OriginPro version 8.5 (OriginLab Corporation, USA). A user-defined double linear curve fit was programmed with Eq. 2.

$$
\begin{aligned}
& m_{\text {absorption }}=m_{0}+k_{0} \cdot \mathrm{t} \quad t<t_{c} \\
& m_{\text {elimination }}=m_{0}+k_{0} \cdot t_{c}+k_{1}\left(\mathrm{t}-\mathrm{t}_{\mathrm{c}}\right) t \geq t_{c}
\end{aligned}
$$

where $m$ is the weight $(\mathrm{g})$ and $t$ is the time $(\mathrm{s})$.

If $m_{a}$ and $m_{e}$ are set equal to 0 and Eq. 2 is solved for $t$, the following equations are obtained:

$t_{0}=\frac{-m_{0}}{k_{0}}$

$t_{1}=t_{c}-\frac{m_{0+} k_{0} \cdot t_{c}}{k_{1}}$ 
a

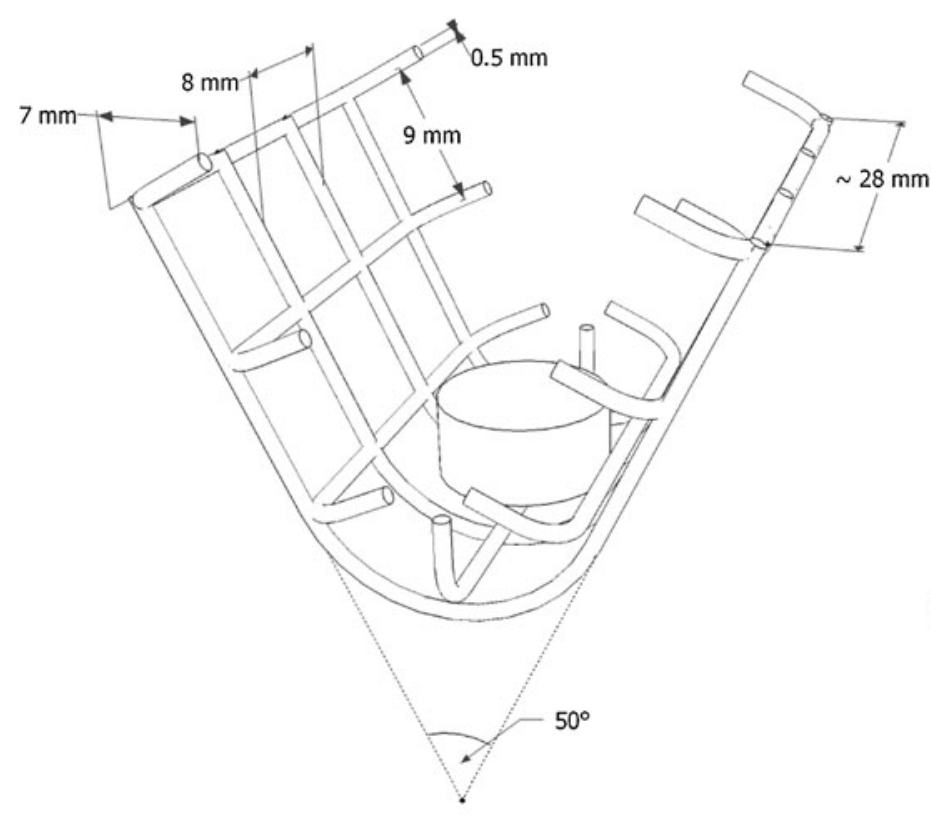

b

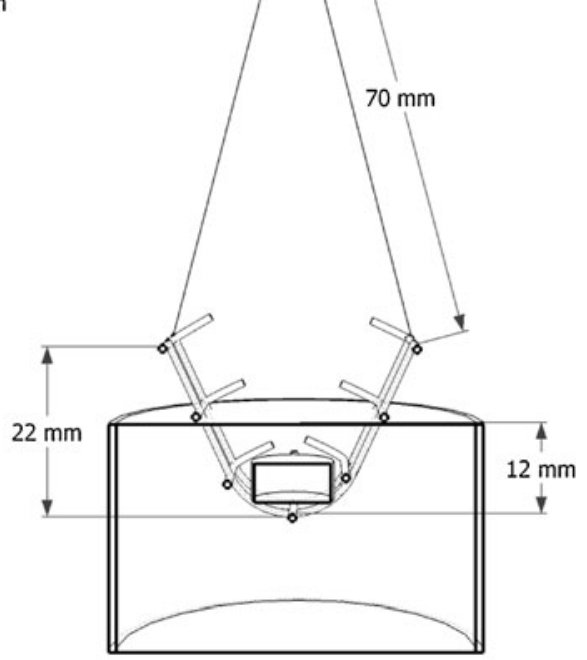

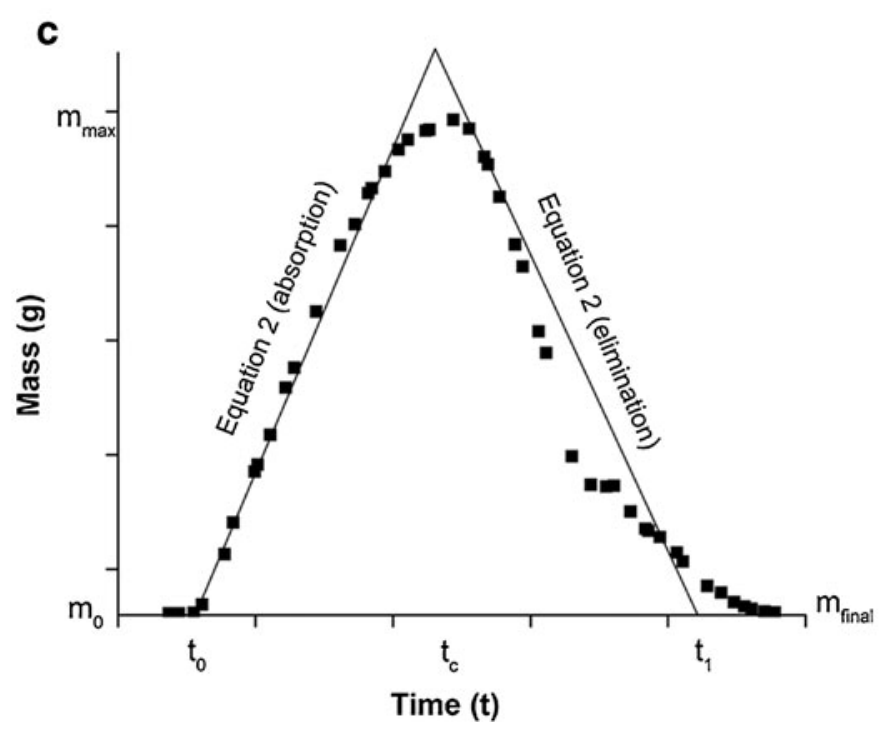

Fig. I (a) Schematic representation of the basket. (b) Schematic representation of the experimental setup for measuring the residence time. (c) Schematic representation of the mass versus time plot from the tensiometer software.

To calculate the residence time, Eq. 3 was used.

$\Delta t=t_{1}-t_{0}=t_{c}-\frac{m_{0+} k_{0} \cdot t_{c}}{k_{1}}-\frac{-m_{0}}{k_{0}}$

In addition to the residence time, the disintegration degree was calculated with Eq. 4:

$n=\left(1-\frac{m_{\text {final }}}{m_{\text {max }}}\right) \cdot 100$

where $\mathrm{n}$ is the disintegration degree $(\%)$ and $\mathrm{m}$ is the weight (g). For $\mathrm{m}_{\max }$ the weight at time point $\mathrm{t}_{\mathrm{c}}$ was used, and $\mathrm{m}_{\text {final }}$ is the weight at leveling off of the profile (Fig. 1c).

\section{Kinetics of Water Absorption (Tensiometer)}

Water absorption capacity of the tablets $(n=3)$ for each lot was measured with a tensiometer (Krüss Processor Tensiometer $\mathrm{K} 100 \mathrm{MK} 2$, Germany) in a water bath $\left(37^{\circ} \mathrm{C} \pm 1^{\circ} \mathrm{C}\right)$. The tablet was placed in a glass tablet holder with a ceramic filter bottom. With the help of the software, time was plotted against mass gain. The slope of this function indicated the speed of water absorption, and the saturation level corresponded to the relative amount of absorbed water. To calculate the slope, the values for the time points between 6 and $9 \mathrm{~s}$ were taken into account. OriginPro version 8.5 
(OriginLab Corporation, USA) was used for curve fitting and the evaluation of tensiometer plots.

\section{RESULTS}

\section{Properties of Fillers (F) and Disintegrants (D)}

Figure 2a-c shows SEM pictures of FCG at different magnifications. The size of the FGC particles was around $7 \mu \mathrm{m}$. The particles showed a multitude of thin lamellae that formed a porous meshwork. Figure $2 \mathrm{~d}$ illustrates the mercury porosimetry plot of FGC.

Table I shows the true densities and medians of the particle diameter of the used substances. With the BET method a specific surface area of $62.14 \pm 0.19 \mathrm{~m}^{2} / \mathrm{g}$ was measured for the FCC particles.

\section{Evaluation of Tablet Properties}

Table II lists the properties of the tablets. At the same volume and hardness $(100 \mathrm{~N})$, the tablets with FCG and MCG 102 were the lightest (around $500 \mathrm{mg}$ ). By comparison, CS90 tablets were approx. 1.7 times heavier (approx. $840 \mathrm{mg}$ ) than the tablets consisting of FCG and MCC 102. Friability was $1.0 \%$ to $1.7 \%$ for all tablets except the formulations with MCC 102, where a friability of approx. $0.5 \%$ was reached. Although volume and hardness of the tablets were kept constant, porosity of the tablets varied strongly between the different tablet formulations. Tablet formulations with FCC had a porosity of over $60 \%$ whereas the MCC 102-based tablets exhibited a porosity of only $40 \%$ at the same weight. With porosities of about $25 \%$ and $35 \%$, the tablets consisting of FlowLac and MCC burst were less porous than MCG 102 tablets. Formulations with CS90 had a porosity of approx. $35 \%$ and weighed approx. $840 \mathrm{mg}$.

Calcium carbonate Natur 120 was not suitable for the preparation of tablets with the desired properties. The target hardness $(100 \mathrm{~N})$ was not reached due to capping of the tablets.

Table III shows the residence times and disintegration degrees obtained after a double linear curve fit of tensiometer weight versus time plots (Fig. 1).

In addition, Table III indicates the speed of water absorption and amount of absorbed water after $90 \mathrm{~s}$. Some formulations with FCG, MCG 102, and MCG burst reached a water absorption speed of more than $50 \mathrm{mg} / \mathrm{s}$. Only MCC 102 and MCC burst formulations absorbed water at a speed of more than $100 \mathrm{mg} / \mathrm{s}$. The formulations with MCC burst showed the highest absolute amount of absorbed water.

As pointed out above, an ODT should disintegrate within $3 \mathrm{~min}$ if tested with the standard disintegration test according to the European Pharmacopeia (11). Figure 3 illustrates the influence of tablet composition on residence time. The horizontal line indicates a residence time of 3 min. With the fillers FCG and FlowLac, three formulations in each case had a residence time of less than $3 \mathrm{~min}$. In comparison with FlowLac, the FCG formulations had a significantly shorter residence time. FCG formulations showed
Fig. 2 (a-c) SEM pictures of FCC (magnifications: $(\mathbf{a}) \times 300$, (b) $\times 3,000$, and $(\mathbf{c}) \times 10,000)$. (d) Mercury porosimetry plot of FCC.
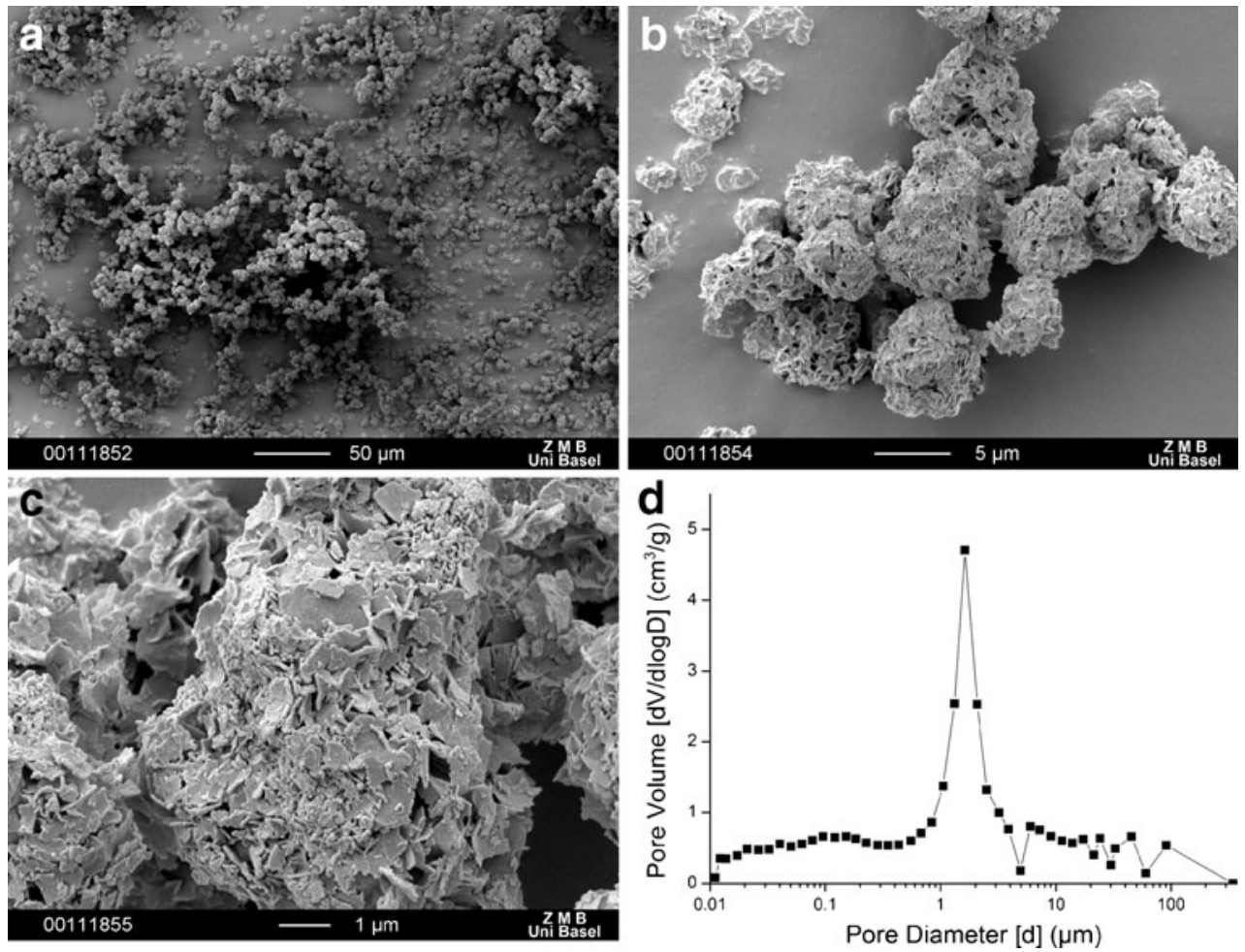
Table I True Density and Median Particle Diameter of the Substances (Where F Stands for Function as Filler and D Stands for Disintegrant)

\begin{tabular}{lllc}
\hline Substance & $\begin{array}{l}\text { Function in a } \\
\text { formulation }\end{array}$ & $\begin{array}{l}\text { True density } \\
\left(\mathrm{g} / \mathrm{cm}^{3}\right)\end{array}$ & $\begin{array}{c}\text { Median particle } \\
\text { diameter }(\mu \mathrm{m}) \pm \mathrm{SD}\end{array}$ \\
\hline FCC & F & 2.7382 & $7.28 \pm 0.05$ \\
Barcroft CS90 & F & 2.5233 & $163.52 \pm 10.00$ \\
MCC I02 & F & 1.5583 & $120.65 \pm 1.31$ \\
FlowLac & F & 1.5412 & $150.37 \pm 2.19$ \\
MCC burst & F+D & 1.5337 & $64.04 \pm 0.14$ \\
AcDiSol & D & 1.5996 & $43.74 \pm 0.06$ \\
VivaStar & D & 1.4778 & $41.20 \pm 0.12$ \\
Kollidon CL & D & 1.2374 & $91.64 \pm 0.81$ \\
\hline
\end{tabular}

fast disintegration comparable to that of MCG burst and MCC 102 formulations. It is important to note that FCC formulations compared well with the reference tablets, risperidone oro. On the other hand, it has to be kept in mind that FCC had to be used in combination with a disintegrant to trigger the fast dispersion. For all tablets with a residence time below $3 \mathrm{~min}$, a disintegration degree between $85 \%$ and $100 \%$ was calculated. Nevertheless, Table III shows that not all of the tablet formulations had residence times below $3 \mathrm{~min}$. We marked the residence time values as $\infty$ if calculated residence time $(\Delta \mathrm{t})$ indicated that water absorption was not followed by tablet disintegration.

\section{DISCUSSION}

\section{Tensiometer Method}

The present work describes a novel strategy for the design of orally dispersible tablets (ODT). Functionalized calcium carbonate (FCG) was used as the main pharmaceutical excipient for ODTs, which are characterized by a very short disintegration time (i.e. $<10 \mathrm{~s}$ ). This rapid process is a challenge, in that conventional disintegration protocols according to the European Pharmacopeia cannot be used. This standard method relies on a vertically moving sample holder. This leads to forced disintegration of tablets due to mechanical stress. For example, formulations containing spray dried calcium carbonate (i.e. the Barcroft formulations), did not disintegrate in an unstirred solution. Upon agitation only, tablet fragments are dislocated from the tablet surface. FlowLac based formulations

Table II Tablet Properties

\begin{tabular}{|c|c|c|c|c|c|c|}
\hline Tablet formulation & $\begin{array}{l}\text { Diameter } \\
(\mathrm{mm})(n=13)\end{array}$ & $\begin{array}{l}\text { Thickness } \\
(\mathrm{mm})(n=13)\end{array}$ & $\begin{array}{l}\text { Weight (mg) } \pm S D \\
(n=13)\end{array}$ & $\begin{array}{l}\text { Hardness } \\
(N) \pm S D(n=3)\end{array}$ & $\begin{array}{l}\text { Friability (\%) } \\
(n=1)\end{array}$ & Porosity (\%) \\
\hline FCC & || $.02 \pm 0.0 \mid$ & $5.30 \pm 0.02$ & $499.4 \pm 2.9$ & $117.3 \pm 15.0$ & 1.06 & 64 \\
\hline $\mathrm{FCC}+3 \% \mathrm{AcDiSol} \otimes$ & || $.03 \pm 0.0 \mid$ & $5.41 \pm 0.01$ & $498.9 \pm 1.9$ & $99.7 \pm 9.6$ & 1.32 & 64 \\
\hline $\mathrm{FCC}+3 \%$ Viva Star ${ }^{\circledR}$ & || $.0| \pm 0.0|$ & $5.36 \pm 0.05$ & $502.3 \pm 0.8$ & $107.0 \pm 3.5$ & 1.67 & 64 \\
\hline 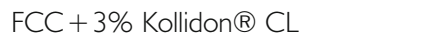 & $|1.02 \pm 0.0|$ & $5.14 \pm 0.01$ & $499.2 \pm 1.0$ & $116.7 \pm 19.2$ & 1.18 & 62 \\
\hline $\mathrm{FCC}+3 \% \mathrm{MCC}$ burst & || $.03 \pm 0.0 \mid$ & $5.20 \pm 0.09$ & $500.8 \pm 1.6$ & $1 \mid 1.7 \pm 21.1$ & 1.10 & 63 \\
\hline Barcroft $^{\text {TM }}$ CS90 & $11.07 \pm 0.00$ & $5.47 \pm 0.01$ & $851.7 \pm 1.4$ & $95.3 \pm 1.2$ & 1.12 & 36 \\
\hline Barcroft $^{\mathrm{TM}} \mathrm{CS} 90+3 \%$ AcDiSol ${ }^{\circledR}$ & $11.08 \pm 0.00$ & $5.58 \pm 0.01$ & $845.3 \pm 1.2$ & $88.3 \pm 2.5$ & 1.25 & 37 \\
\hline Barcroft $^{\mathrm{TM}}$ CS $90+3 \%$ Viva Star ${ }^{\circledR}$ & $|1.08 \pm 0.0|$ & $5.50 \pm 0.01$ & $845.9 \pm 1.3$ & $94.7 \pm 2.9$ & 1.14 & 36 \\
\hline Barcroft ${ }^{\mathrm{TM}} \mathrm{CS} 90+3 \%$ Kollidon ${ }^{\circledR} \mathrm{CL}$ & $11.07 \pm 0.00$ & $5.51 \pm 0.01$ & $833.0 \pm 1.5$ & $98.3 \pm 3.8$ & 1.12 & 37 \\
\hline Barcroft $^{\text {TM }}$ CS90 $+3 \%$ MCC burst & $11.06 \pm 0.00$ & $5.49 \pm 0.01$ & $836.9 \pm 1.1$ & $95.7 \pm 0.6$ & 1.20 & 36 \\
\hline 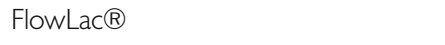 & $|1.05 \pm 0.0|$ & $5.32 \pm 0.01$ & $594.4 \pm 2.7$ & $88.3 \pm 3.2$ & 1.46 & 24 \\
\hline FlowLac $(\circledR)+3 \%$ AcDiSol $®$ & $\mid 1.06 \pm 0.01$ & $5.33 \pm 0.01$ & $593.3 \pm 1.3$ & $86.3 \pm 2.1$ & 1.28 & 25 \\
\hline FlowLac ${ }^{\circledR}+3 \%$ Viva Star $\AA$ & $11.06 \pm 0.00$ & $5.34 \pm 0.01$ & $598.7 \pm 0.8$ & $88.3 \pm 5.0$ & 1.40 & 24 \\
\hline FlowLac $®+3 \%$ Kollidon $® C L$ & $11.06 \pm 0.00$ & $5.35 \pm 0.02$ & $595.0 \pm 1.2$ & $89.3 \pm 3.2$ & 1.50 & 24 \\
\hline FlowLac ${ }^{\circledR}+3 \%$ MCC burst & $|1.06 \pm 0.0|$ & $5.34 \pm 0.01$ & $605.4 \pm 2.7$ & $97.3 \pm 7.8$ & 1.16 & 23 \\
\hline MCC 102 & $|1.06 \pm 0.0|$ & $5.53 \pm 0.02$ & $489.0 \pm 3.6$ & $93.0 \pm 7.5$ & 0.54 & 41 \\
\hline MCC I $02+3 \%$ AcDiSol $\circledast$ & $|1.06 \pm 0.0|$ & $5.55 \pm 0.02$ & $494.0 \pm 2.8$ & $93.3 \pm 2.1$ & 0.38 & 41 \\
\hline MCC $102+3 \%$ Viva Star ${ }^{\circledR}$ & $|1.07 \pm 0.0|$ & $5.54 \pm 0.03$ & $498.3 \pm 2.3$ & $96.0 \pm 1.0$ & 0.51 & 40 \\
\hline MCC $102+3 \%$ Kollidon ${ }^{\circledR}$ CL & $\mid 1.06 \pm 0.01$ & $5.55 \pm 0.02$ & $487.9 \pm 1.8$ & $98.3 \pm 3.5$ & 0.48 & 41 \\
\hline MCC $102+3 \%$ MCC burst & || $.07 \pm 0.0 \mid$ & $5.54 \pm 0.02$ & $493.6 \pm 2.0$ & $92.3 \pm 3.5$ & 0.59 & 41 \\
\hline MCC burst & $|1.10 \pm 0.0|$ & $5.83 \pm 0.03$ & $566.6 \pm 2.9$ & $88.7 \pm 3.8$ & 1.52 & 34 \\
\hline MCC burst $+3 \%$ AcDiSol ${ }^{\circledR}$ & $|1.09 \pm 0.0|$ & $5.75 \pm 0.03$ & $563.3 \pm 1.9$ & $94.0 \pm 3.5$ & 1.38 & 34 \\
\hline MCC burst $+3 \%$ Viva Star ${ }^{\circledR}$ & $|1.08 \pm 0.0|$ & $5.84 \pm 0.02$ & $573.8 \pm 1.8$ & $90.0 \pm 0.0$ & 1.64 & 33 \\
\hline MCC burst $+3 \%$ Kollidon ${ }^{\circledR} \mathrm{CL}$ & $|1.10 \pm 0.0|$ & $5.82 \pm 0.02$ & $566.5 \pm 1.3$ & $86.7 \pm 3.8$ & 1.53 & 34 \\
\hline
\end{tabular}


Table III Calculated Parameters for Residence Time, Disintegration Degree, and Kinetic of Water Absorption

\begin{tabular}{|c|c|c|c|c|c|}
\hline Tablet formulation & $\begin{array}{l}\text { Residence } \\
\text { time (s) }\end{array}$ & $\begin{array}{l}\text { Disintegration } \\
\text { degree }(\%)\end{array}$ & $\begin{array}{l}\text { Disintegration } \\
\text { type (I-IV) }\end{array}$ & $\begin{array}{l}\text { Amount of absorbed } \\
\text { water after } 90 \mathrm{~s}(\mathrm{~g})\end{array}$ & $\begin{array}{l}\text { Speed of water } \\
\text { absorption }(\mathrm{mg} / \mathrm{s})\end{array}$ \\
\hline FCC & $\infty$ & 0 & $\|$ & $0.189 \pm 0.011$ & $4.5 \pm 0.33$ \\
\hline $\mathrm{FCC}+3 \% \mathrm{AcDiSol}{ }^{\circledR}$ & 8.92 & 100 & I & $1.232 \pm 0.018$ & $80.4 \pm 2.69$ \\
\hline $\mathrm{FCC}+3 \%$ Viva Star ${ }^{\circledR}$ & 11.94 & 100 & । & $1.599 \pm 0.055$ & $86.8 \pm 3.95$ \\
\hline FCC $+3 \%$ Kollidon $® \mathrm{CL}$ & 9.53 & 100 & I & $0.816 \pm 0.007$ & $37.9 \pm 0.92$ \\
\hline $\mathrm{FCC}+3 \%$ MCC burst & 4858.26 & 2 & $\|$ & $0.229 \pm 0.008$ & $4.9 \pm 0.54$ \\
\hline Barcroft $^{\text {TM }}$ CS90 & $\infty$ & 0 & $\|$ & $0.115 \pm 0.013$ & $0.7 \pm 0.09$ \\
\hline Barcroft $^{\text {TM }}$ CS90 + 3\% AcDiSol ${ }^{\circledR}$ & 7703.4 & 4.7 & $\|$ & $0.080 \pm 0.033$ & $1.9 \pm 0.05$ \\
\hline Barcroft $^{\mathrm{TM}}$ CS90 + 3\% Viva Star ${ }^{\circledR}$ & 197.68 & 100 & III & $0.263 \pm 0.015$ & $5.9 \pm 0.29$ \\
\hline Barcroft $^{\mathrm{TM}} \mathrm{CS} 90+3 \%$ Kollidon ${ }^{\circledR} \mathrm{CL}$ & $\infty$ & 0 & $\|$ & $0.074 \pm 0.037$ & $1.6 \pm 0.24$ \\
\hline Barcroft $^{\text {TM }}$ CS90 $+3 \%$ MCC burst & $\infty$ & 0 & $\|$ & $0.113 \pm 0.021$ & $1.1 \pm 0.19$ \\
\hline 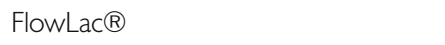 & 61.92 & 100 & III & $0.311 \pm 0.044$ & $5.4 \pm 2.06$ \\
\hline FlowLac ${ }^{\circledR}+3 \%$ AcDiSol ${ }^{\circledR}$ & 127.85 & 100 & III & $0.322 \pm 0.016$ & $5.5 \pm 0.29$ \\
\hline FlowLac $®+3 \%$ Viva Star $\AA$ & 194.2 & 100 & III & $0.667 \pm 0.026$ & $16.2 \pm 1.64$ \\
\hline FlowLac ${ }^{\circledR}+3 \%$ Kollidon ${ }^{\circledR} \mathrm{CL}$ & 65.09 & 100 & III & $0.375 \pm 0.017$ & $9.8 \pm 0.33$ \\
\hline FlowLac ${ }^{\circledR}+3 \%$ MCC burst & 64.57 & 85 & III & $0.344 \pm 0.045$ & $9.1 \pm 0.95$ \\
\hline MCC 102 & $\infty$ & 0 & $\|$ & $0.807 \pm 0.040$ & $79.2 \pm 17.95$ \\
\hline MCC I $02+3 \%$ AcDiSol $\circledast$ & 1681.78 & 47.2 & IV & $1.306 \pm 0.017$ & $82.3 \pm|3.6|$ \\
\hline MCC 102 + 3\% Viva Star ${ }^{\circledR}$ & 9.65 & 99.1 & I & $1.840 \pm 0.050$ & $152.9 \pm 27.09$ \\
\hline MCC I02 + 3\% Kollidon ${ }^{\circledR}$ CL & $\infty$ & 0 & IV & $0.877 \pm 0.016$ & $70.1 \pm 15.83$ \\
\hline MCC $102+3 \%$ MCC burst & $\infty$ & 0 & $\|$ & $0.847 \pm 0.044$ & $71.0 \pm 12.97$ \\
\hline MCC burst & $\infty$ & 0 & IV & $1.74 \mid \pm 0.059$ & $96.6 \pm 5.63$ \\
\hline MCC burst + 3\% AcDiSol $\AA$ & 5.92 & 96.3 & I & $1.864 \pm 0.052$ & $70.9 \pm 3.22$ \\
\hline MCC burst + 3\% Viva Star $\AA$ & 10.4 & 100 & I & $2.347 \pm 0.034$ & $98.1 \pm 4.64$ \\
\hline MCC burst $+3 \%$ Kollidon $® C L$ & $\infty$ & 0 & IV & $1.826 \pm 0.054$ & $104.9 \pm 13.24$ \\
\hline Risperidone oro & 17.26 & 100 & I & - & - \\
\hline
\end{tabular}

have a similar behavior in that tablets are fractured by agitation. However, this "accelerated" or "forced" disintegration does not reflect the intended use of our ODT formulations. Here, disintegration in unstirred liquid (i.e. in a spoon prior to oral administration) is needed. We were therefore forced to develop our own disintegration method. As expected, the disintegration time for most formulations was shorter for the standard method as compared to our tensiometer method. In particular, MCG based formulations swell only and do not disintegrate if not agitated. An additional advantage of our tensiometer based method is its ability to monitor rapid disintegration processes with very high precision. In addition, a slight modification of the experimental setup allows for quantification of the absorbed amount of water. Thereby, the type, volume, and temperature of fluid can be varied.

\section{FCC as a New Pharmaceutical Excipient for the Production of ODTs}

Comparison between FCC and Barcroft showed considerable differences in the porosity. FCC-containing formulations (with disintegrants) showed the best results. Formulations combining
FCG with a disintegrant disintegrated/dispersed within a few seconds. Thereby, the mode of action of the different disintegrants had no significant influence on the residence time. Furthermore, all formulations of FCG combined with disintegrants belonged to the disintegration type I and showed a disintegration degree of $100 \%$. We successfully produced tablets with marked porosity and high hardness.

\section{Properties of FCC}

Several studies have demonstrated that porosity has a surprisingly low impact on the disintegration behavior of FCC. Figure 4 correlates speed of water absorption and the absorbed amount of water after $90 \mathrm{~s}$ for FCC combined with different excipients. Speed of water absorption and absorbed amount of water after $90 \mathrm{~s}$ for each formulation were influenced by the disintegrants only.

For FCC as well as all other excipients, no correlation could be shown between the tablet weight and disintegration degree (Table II and III). Disintegration degree was only dependent on the composition of the tablet formulations. Residence time also depended on the tablet composition and 
Fig. 3 Influence of tablet composition on residence time.

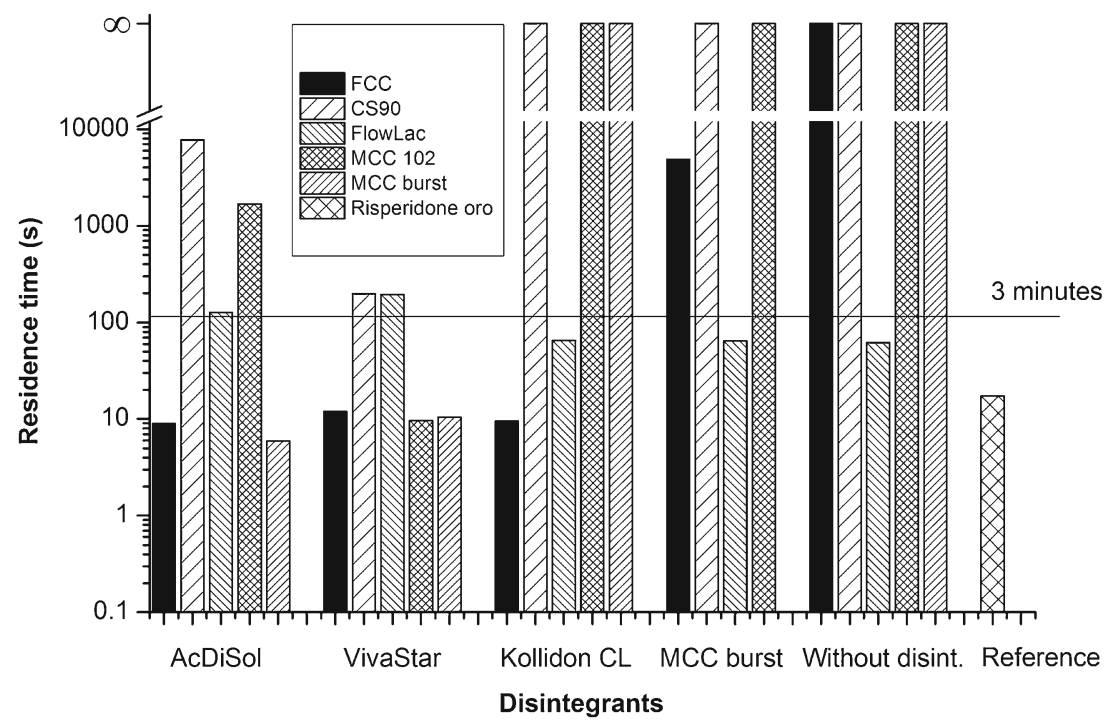

was not affected by the porosity or weight of the tablets. This latter finding was surprising since it has been suggested recently that porosity might be an important property of ODTs (26). Again, the combination of filler and disintegrants seems to be the decisive factor, which appears to be a unique property of FCG. All other excipients studied did not show such a linear correlation (data not shown). This result suggests that the speed of water absorption is modulated by disintegrants. In the case of FCG, water absorption is a prerequisite for disintegration since pure FCC neither absorbs water nor disintegrates. Thus, the choice of a specific disintegrant is not a critical factor.

From the percolation theory point of view, disintegration occurs above critical concentrations (threshold) of the disintegrant (33). In our study, all formulations had disintegrant concentrations close to the theoretically predicted

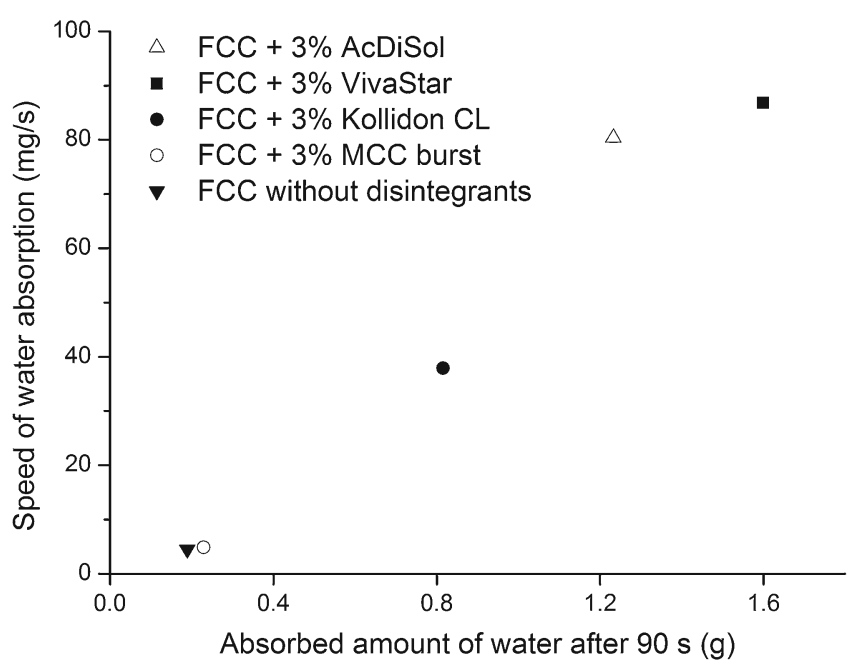

Fig. 4 Correlation plot between speed of water absorption and absorbed amount of water after $90 \mathrm{~s}$. critical value, i.e., approx. $3 \%(v / v)$. At these concentrations, the rate of disintegration is mostly governed by the type of disintegrant rather than by tablet porosity (33).

\section{Definition of Disintegration Patterns}

We were able to distinguish four typical disintegration patterns (Table III and Fig. 5).

First, excipients such as FCG and the commercial reference, ODT formulation of risperidone oro, showed a classical disintegration pattern. Initially, absorption of water is faster than disintegration (increase in mass). After reaching a peak, the tablet continuously dispersed (decrease in mass) into very small particles. This desirable property has been termed disintegration type I. In sharp contrast, non-modified calcium carbonate particles (Barcroft) did not disintegrate. This profile was characterized by fast initial water absorption only. After saturating the pores with water, the speed of the water absorption declined continuously. Some formulations reached a plateau, whereas other formulations were still able to absorb more water, forming a large swollen lump. This profile was defined as disintegration type II. FlowLac was a typical representative of disintegration type III, which was characterized by nonuniformity in the disintegration phase caused by larger fragments falling off the tablet and then through the mesh. These parts needed some more time on the bottom of the beaker to disperse completely. We could not establish whether the fragments that had come loose were still dry on the inside. Finally, cellulose-based excipients (i.e., MCG 102 and MCG burst) combined properties of type I and type II disintegration patterns: initial phase of swelling followed by partial disintegration. This profile termed disintegration type IV.

Owing to the new and very sensitive tensiometer method, ODTs could be categorized based on their disintegration profiles (Table III). 

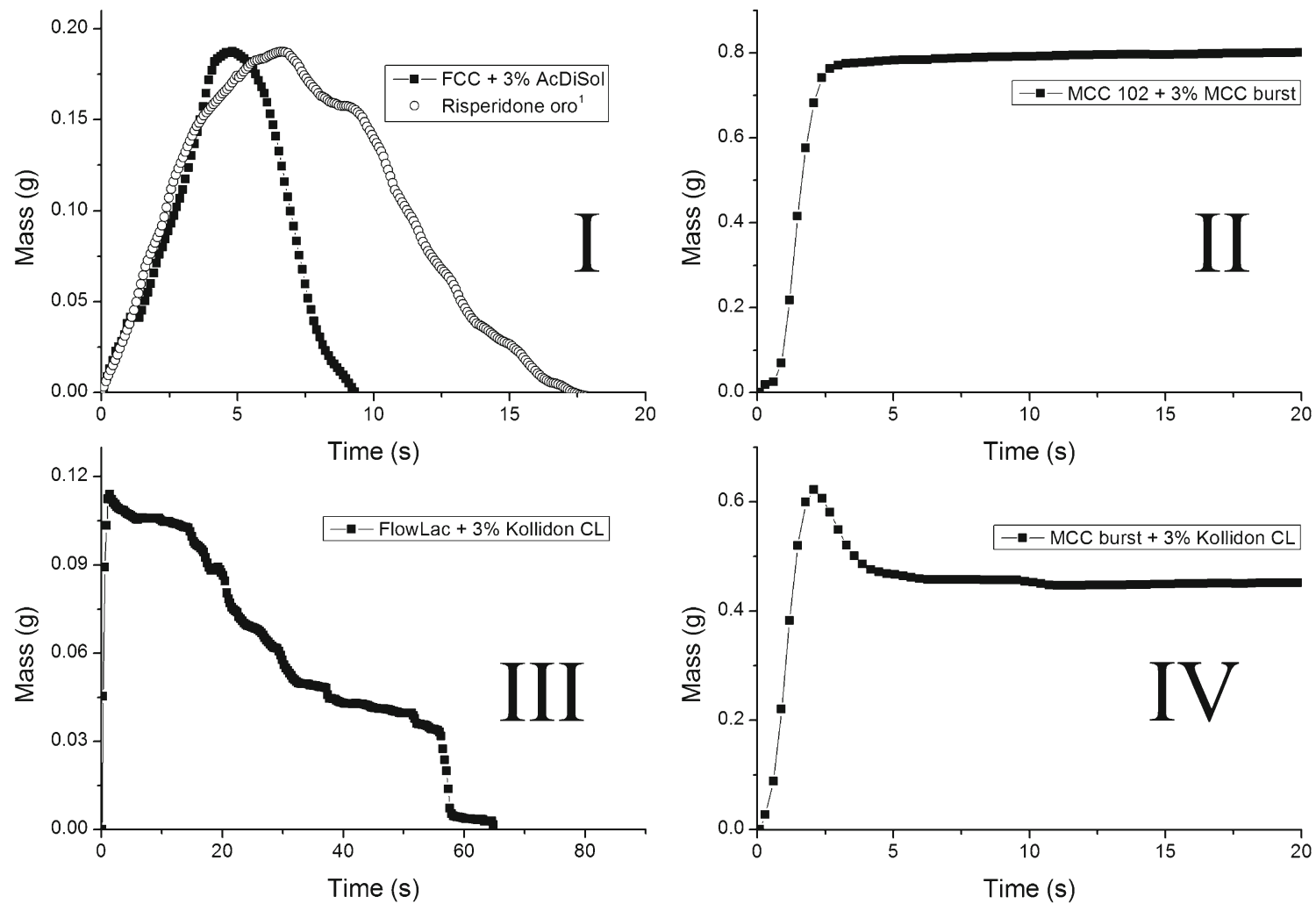

Fig. 5 Tensiometer plots for 4 types of disintegration kinetics (mass versus time). Re-normalized curve (with mass maximum at $0.0223 \mathrm{~g}$ ).

\section{Quantitative Model for Residence Time}

Disintegration profiles can be evaluated using a user-defined double linear curve fit model. In the majority of cases, the values of residence time determined from the tensiometer plot (Fig. 5) agreed well with the calculated values in Table III. Quantitative evaluation for profiles of type III was difficult due to the larger parts of the tablets that had fallen through the basket mesh (i.e., without dispersing/disintegrating), hence shortening the residence time. Another limitation of the model was the discrepancy between measured and calculated values for residence time for a few formulations that showed an exponential function within the tensiometer plot.

It should be emphasized, that disintegration of tablets is a complex process. Figure 1c shows a disintegration profile, which is characterized by a series of sequential events. In a first step, the tablet was wetted by the medium, followed by medium absorbance and disintegration. Thus, the tablet mass increased until equilibrium was reached between liquid sorption and mass decrease due to disintegration. Afterwards, the disintegration predominated the water sorption resulting in a net loss of mass.

In many instances (Fig. 5), the disintegration pattern is more complex. For example, some materials first soak up liquid very fast and subsequently start to disintegrate by heterogeneous fractionation. Other materials like FCC soak up water at moderate speeds, leading to continuous disintegration and loss of mass.

Several mathematical models can be used to describe these processes. For example, the concurrent effects could be modeled by the system of two differential equations (here combined into one equation):

$\frac{d}{d t} m(t)=M_{0} e^{-k_{a} t}-k_{e} m(t) ;$

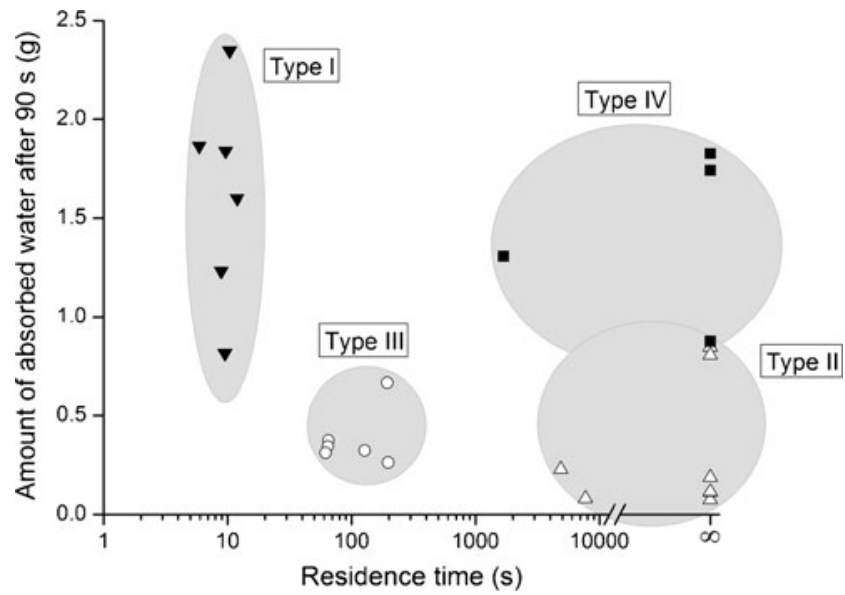

Fig. 6 Correlation plot between the amount of absorbed water after $90 \mathrm{~s}$ and residence time for the different disintegration types. 
where $\mathrm{m}(\mathrm{t})$ is mass detected by tensiometer, $\mathrm{t}$ is the time, $\mathrm{M}_{0}$ is compact mass in the test media, and $\mathrm{K}_{\mathrm{a}}$ and $\mathrm{K}_{\mathrm{e}}$ are the absorption and disintegration speed constants, respectively.

However, the obtained model - although it's good illustrative properties - does not produce fits of experimental data of sufficient quality. The reason for this is that the disintegration behavior is not monotonous on the whole disintegration timeline. For example, the lactose-based formulations were disintegrating by losing larger pieces of mass, hence producing "step-wise" profiles. Such profiles produce poor fitting of the exponential equations, hence we had to discard this approach. In order to take into account such inhomogeneous effects the differential model should be modified or substituted by another, - perhaps, discrete - model.

An alternative polynomial fit of the curves was not favorable due to a potential risk of over fitting.

For this publication we used a simplified linear model, which gave best results in all encountered situations. Utilizing this approach, we can determine the residence time of the pharmaceutical compact on the tensiometer sample basket.

\section{Optimal Type I Disintegration of FCC}

Figure 6 shows a correlation plot between the amount of absorbed water after $90 \mathrm{~s}$ and residence time for the different disintegration types. Due to very long or even unlimited residence time, disintegration type II and type IV were of no interest for the production of ODTs. Although the majority of formulations of disintegration type III had a residence time below $3 \mathrm{~min}$, type III was limited by nonuniform disintegration. Disintegration type I showed the shortest residence time and was therefore the most appropriate for producing ODTs. Within type I, the formulations are better the shorter the residence time and the lower the amount of absorbed water after $90 \mathrm{~s}$. The absorbed amount of water is important with respect to patient compliance in the clinical setting. We assume that a pleasant mouth feel can be achieved with tablets dispersing in small amounts of saliva. If more saliva is absorbed by the ODT, patient's mouth feels dry, and swallowing of the tablet becomes difficult. Therefore, we conclude that FCC-based formulations were the best. When combined with disintegrants, FCG formulations showed a disintegration pattern of type I, comparable to that of the market reference drug, risperidone oro.

\section{CONCLUSION}

ODTs are designed to disperse within seconds. The prerequisite for reliable classification and quantification of disintegration properties of ODTs is the availability of a fast analytical method.
In order to compare ODT tablet formulations containing FCG, we introduced a new method to characterize the disintegration/dispersion kinetics and swelling properties of ODTs. With this method we were able to detect the exact amount of absorbed water after 90 s, speed of water absorption, and residence time of a tablet placed on a basket immersed into water with a single instrument.

We conclude that FCG has the required properties to produce ODTs, such as a fast disintegration, and sufficient mechanical strength. To fulfill the requirements for a short disintegration time, the FCG formulations have to contain superdisintegrants. The FCC formulations absorbed smallest amount of water, which would enhance patient compliance in the clinical setting.

FCG is a new pharmaceutical excipient, which can be used to assist in the preparation of orally dispersible tablets. ODTs prepared using FCC as main excipient are characterized by a short disintegration time and high mechanical strength. Thus, drug delivery to the buccal cavity or upper esophageal regions can be achieved. The oral sensation after ingesting FCC particles is expected to be favorable since particles with a particle size below $15 \mu \mathrm{m}$ are not felt in the mouth (34). Further experiments are required to study the friability and flowability of FCG particles being a prerequisite for large scale production.

\section{ACKNOWLEDGMENTS AND DISCLOSURES}

Dr. Maxim Puchkov and Prof. Dr. Jörg Huwyler have contributed equally to the present work. Financial support for this $\mathrm{PhD}$ thesis was kindly provided by Omya limited. We would like to thank Mark Inglin for editorial assistance. Thanks also go to Daniel Mathys for his technical support in connection with electron microscopic examinations.

\section{REFERENCES}

1. Kuchekar B, Badhan A, Mahajan H. Mouth dissolving tablets: a novel drug delivery system. Pharma Times. 2003;35:7-9.

2. Virely P, Yarwood R. Zydis - A novel, fast dissolving dosage form. Manuf Chem. 1990;61:36-7.

3. Corveleyn S, Remon JP. Formulation and production of rapidly disintegrating tablets by lyophilisation using hydrochlorothiazide as a model drug. Int J Pharm. 1997;152(2):215-25.

4. Pebley W, Jager N, Thompson S. Rapidly disintegrating tablet. 1994.

5. Allen LV, Wang B. Process for making a particulate support matrix for making a rapidly dissolving tablet [Internet]. 1996 [cited 2012 Jun 14]. Available from: http://www.google.com/ patents/US5587 180

6. Bhaskaran S, Narmada G. Rapid dissolving tablet a novel dosage form. Indian Pharmacist. 2002;1:9-12.

7. Dobetti L. Fast-melting tablets: developments and technologies. Pharm Tech Europe. 2000;12(9):32-42. 
8. Sreenivas SA. Orodispersible tablets: new-fangled drug delivery system - a review. Indian J Pharm Educ Res. 2005;39(4):177-81.

9. Kumar VD, Sharma I, Sharma V. A comprehensive review on fast dissolving tablet technology. J App Pham Sci. 2011;1(5):50-8.

10. Bi Y, Sunada H, Yonezawa Y, Danjo K. Evaluation of rapidly disintegrating tablets prepared by a direct compression method. Drug Dev Ind Pharm. 1999;25(5):571-81.

11. Pharmacopeia E. 7th ed. Strasbourg (France): Council of Europe; 2011.

12. Food and Drug Administration (FDA). Guidance for industry orally disintegrating tablets [Internet]. 2008 [cited 2012 Nov 1]. Available from: http://www.fda.gov/downloads/Drugs/ GuidanceComplianceRegulatory/Information/Guidances/ ucm070578.pdf

13. McLaughlin R, Banbury S, Crowley K. Orally disintegrating tablets: the effect of recent FDA guidance on ODT technologies and applications. Pharm Technol. 2009;33:18-25.

14. Bi Y, Sunada H, Yonezawa Y, Danjo K, Otsuka A, Iida K. Preparation and evaluation of a compressed tablet rapidly disintegrating in the oral cavity. Chem Pharm Bull. 1996;44(11):2121-7.

15. Shukla D, Chakraborty S, Singh S, Mishra B. Mouth dissolving tablets II: an overview of evaluation techniques. Sci Pharm. 2009;77:327-41.

16. Narazaki R, Harada T, Takami N, Kato Y, Ohwaki T. A new method for disintegration studies of rapid disintegrating tablet. Chem Pharm Bull. 2004;52(6):704-7.

17. Ohta M, Hayakawa E, Ito K, Tokuno S, Morimoto K, Watanabe Y. Intrabuccally rapidly disintegrating tablet [Internet]. 2001 [cited 2012 Feb 1]. Available from: http://www.freepatentsonline.com/ y2001/0014340.html

18. Morita Y, Tsushima Y, Yasui M, Termoz R, Ajioka J, Takayama $\mathrm{K}$. Evaluation of the disintegration time of rapidly disintegrating tablets via a novel method utilizing a CCD camera. Chem Pharm Bull. 2002;50(9):1181-6.

19. Fu Y, Jeong S, Park K. Preparation of fast dissolving tablets based on mannose. ACS Symp Ser. 2006;924:340-51.

20. Harada T, Narazaki R, Nagira S, Ohwaki T, Aoki S, Iwamoto K. Evaluation of the disintegration properties of commercial famotidine $20 \mathrm{mg}$ orally disintegrating tablets using a simple new test and human sensory test. Chem Pharm Bull. 2006;54(8):1072-5.

21. El-Arini S, Clas S. Evaluation of disintegration testing of different fast dissolving tablets using the texture analyzer. Pharm Dev Technol. 2002;7(3):361-71.

22. Abdelbary G, Eouani C, Prinderre P, Joachim J, Reynier J, Piccerelle P. Determination of the in vitro disintegration profile of rapidly disintegrating tablets and correlation with oral disintegration. Int J Pharm. 2005;292(1-2):29-41.
23. Kraemer J, Gajendran J, Guillot A, Schichtel J, Tuereli A. Dissolution testing of orally disintegrating tablets. J Pharm Pharmacol. 2012;64(7):911-8.

24. Massimo G, Catellani PL, Santi P, Bettini R, Vaona G, Bonfanti A, et al. Disintegration propensity of tablets evaluated by means of disintegrating force kinetics. Pharm Dev Technol. 2000;5(2):1639.

25. Welch K, Strømme M. Simultaneous measurement of drug release and liquid uptake in pharmaceutical tablets. J Pharm Sci. 2003;92(6): 1242-9.

26. Pabari RM, Ramtoola Z. Application of face centred central composite design to optimise compression force and tablet diameter for the formulation of mechanically strong and fast disintegrating orodispersible tablets. Int J Pharm. 2012;430(12):18-25.

27. Ridgway CJ, Gane PAC, Schoelkopf J. Modified calcium carbonate coatings with rapid absorption and extensive liquid uptake capacity. Colloids Surf A. 2004;236(1-3):91-102.

28. Rowe RC, Sheskey PJ, Quinn ME. Handbook of Pharmaceutical Excipients. 6th ed. London, UK: Pharmaceutical Press and American Pharmacist Association; 2009.

29. Gane PAC, Buri M, Blum RV, Karth B. Filler or pigment or processed mineral for paper, in particular a pigment containing natural $\mathrm{CaCO} 3$, its manufacturing process, preparations containing it and their applications [Internet]. 2004 [cited 2012 Oct 24]. Available from: http://www.google.com/patents/ US20040020410?dq=patent $+\mathrm{US}+2004 / 0020410+\mathrm{Al} \& \mathrm{hl}=$ en\&sa $=$ X\&ei $=$ YqqHUOTdIcWQhQeUioHoAw\&ved $=$ 0CDEQ6AEwAA

30. Fiedler HP. Fiedler Lexikon der Hilfsstoffe für Pharmazie, Kosmetik und angrenzende Gebiete. Aulendorf: Editio Cantor Verlag; 2002.

31. Krausbauer E. Contributions to a science based expert system for solid dosage form design. [Basel]: University of Basel, Faculty of Science; 2009.

32. Garboczi EJ, Snyder KA, Douglas JF, Thorpe MF. Geometrical percolation threshold of overlapping ellipsoids. Phys Rev E Stat Phys Plasmas Fluids Relat Interdiscip Topics. 1995;52(1):819-28.

33. Krausbauer E, Puchkov M, Betz G, Leuenberger H. Rational estimation of the optimum amount of non-fibrous disintegrant applying percolation theory for binary fast disintegrating formulation. J Pharm Sci. 2008;97(1):529-41.

34. Ishikawa T, Mukai B, Shiraishi S, Utoguchi N, Fujii M, Matsumoto $\mathrm{M}$, et al. Preparation of rapidly disintegrating tablet using new types of microcrystalline cellulose (PH-M series) and low substitutedhydroxypropylcellulose or spherical sugar granules by direct compression method. Chem Pharm Bull. 2001;49(2):134-9. 